\title{
OPTIMIZATION OF INDUSTRIAL FAN SYSTEM USING METHODS LASER
} ALIGNMENT

Original scientific paper

UDC: $621.822 .6: 621.824$

https://doi.org/10.18485/aeletters.2021.6.2.3

\section{Borivoj Novaković ${ }^{1}$, Eleonora Desnica ${ }^{1}$, Ljiljana Radovanović ${ }^{1}$, Rade Ivetić ${ }^{2}$, Luka Đorđević ${ }^{1}$, Dragana Labović Vukić ${ }^{3}$}

${ }^{1}$ University of Novi Sad, Technical Faculty “Mihajlo Pupin”, Republic of Serbia

${ }^{2}$ IVETIM, Zrenjanin, Republic of Serbia

${ }^{3}$ University of Montenegro, Faculty of Maritime Studies, Kotor, Montenegro

\begin{abstract}
:
The research in this paper aimed to show the importance of axial alignment on the example of maintaining a technical system. In this paper, the importance of alignment is examined on industrial fans. The technical system on which the alignment was performed reached the anticipated bearing life of 23,650 operating hours prescribed by the manufacturer, while the technical system on which the alignment was not performed was exposed to excessive load by a misalignment shaft. As a result, it did not meet the expected technical expectations, and it canceled at 5,400 hours of work. Research has shown that the application of alignment can increase

the service life of bearings by 4.38 times on axles on which no alignment has been performed.

Implementation of modern maintenance concepts, using appropriate methods of technical diagnostics aim to optimize the operation of industrial systems for a short period of time and with as few downtimes as possible. The authors of the paper presented the method of laser alignment in order to bring the industrial fan system into optimal operation. In addition to laser alignment, the condition of the system was checked by vibro diagnostics, before and after access by laser method. The paper presents all measurements performed with vibration analysis devices as well as a visual display of the state of the system during the laser alignment check of an industrial fan. Misalignment leads to incorrect operation, which in the case of electric motors and fans is most often reflected in damage in the form of distortion of the shaft or damage to the bearings.
\end{abstract}

\section{ARTICLE HISTORY}

Received: 22.02.2021.

Accepted: 18.05.2021.

Available: 30.06.2021.

\section{KEYWORDS}

Maintenance, Diagnostics, Vibration, Misalignment, Fan, Bearing

\section{INTRODUCTION}

All aspects of industrial systems, both in the field of production, construction, and maintenance, tend towards a certain level of automation. The concept of automation is characterized as one of the processes that facilitate activities in all aspects of the industry, from the initial phase of product creation and its components to the final stages of exploitation and maintenance. With the expansion of digitalization and the advent of the Industry 4.0 concept, the aim is to optimize industrial production and a thorough approach to collecting important data [1].

The modern concept that deals with a detailed analysis of all aspects of maintenance is called the CBM concept, i.e., conditional maintenance (Conditional Based Maintenance). In order to implement this concept in a thorough, high-quality way, it is necessary to have appropriate equipment 
within the maintenance (vibroanalyzer, XT laser device), i.e., the so-called "condition monitoring" (Conditional Monitoring).

The forecast is the ability to predict the future condition of the machine based on the current condition of the machine shown by its diagnostics and based on data on the history of machine failures [2]. In order for proactive maintenance, to which this concept belongs, to be carried out, the forecast of the future state of the system must integrate the maximum of the available information in order to bring the conclusion about the state of a system as realistic as possible [3].

Predictive maintenance has been identified as a leading segment of the popular analytics industry. The ratio of the potential of the predictive way of maintenance and its actual application is at a very low level, great potentials and a small degree of utilization of this type of technology are one of the brakes on the development of industrial analytics. The records that are monitored represent a complex amount of data. However, research shows that sometimes this data is of no use to organizations that have implemented this type of maintenance. If such occurrences are frequent, i.e., in order to improve risk assessment, it is necessary to introduce new methods for risk assessment $[4,5]$. Diagnosis and maintenance as a whole represent a complex functional system [6]. The method of vibration measurement is probably the best-known method within the scope of this concept, as the most widespread concept in this segment [7].

Non-compliance is one of the most common phenomena, i.e., detected errors in rotating machines. It causes irregular vibrations and shortens the parts' lives mounted on the shaft, such as bearings and gears [8]. Failure detection and identification of the type of failure are very important to ensure the safety of the machine and the quality of production $[9,10]$.

Misalignment of the coupling in the rotor system can bring in non-linear forces and moments, which may cause premature failures to the rotary machines [11]. The coupling of shaft misalignment and crack in rotor systems will produce more complex non-linear dynamic characteristics in the vibration response and increase the difficulty of the fault identification greatly [12].

Many research papers have dealt with the issue of the reliability of technical systems of roller bearings. Thus, research on the analysis of ball bearing reliability on the compressor piston crankshaft showed an identical possibility of monitoring the system reliability by monitoring the axial clearances and bearing temperature [13]. The significance and problems of non-alignment of agricultural cardan shafts and its impact with reduced reliability of needle bearings on cardan joints are presented in research [14-16]. The development of a methodology for optimizing software alignment of drive shafts is presented in the research [17].

On rotary machines, non-alignment shafts increase vibration and friction, which causes increased energy consumption and premature damage to bearings and seals [18]. In order to eliminate the above, laser alignment techniques are now used in measuring alignment, the main advantages of which are non-contact measurement, fast response, and high measurement accuracy [19].

\section{MATERIAL AND METHOD OF WORK}

The conducted research aimed to point out the importance, i.e., the reliability of the technical systems on which the alignment of the shaft was done. For the purposes of the research, a comparative analysis of the service life of bearings on the technical fan system was performed:

$>$ on which the alignment of the shaft is performed and

$>$ on which the shaft alignment has not been performed.

For the purposes of the research, vibration measurements were performed on an industrial fan (Figure 1) using laser adjustment. The tested technical system is located in the production plant of the factory Farmina Pet Foods DOO. For the needs of the research, measuring equipment was used:

$>\quad$ Vibrobalans 5 analyzer and

$>$ EasyLaser XT440 laser device.

\section{RESEARCH RESULTS}

When diagnosing the condition of the technical system, it is necessary to consider the history of system maintenance and all the necessary data about the system. The paper presents research results an FFT analysis of the spectrum of vibrations measured on an industrial fan before and after approaching the precise laser alignment of the axes of the shafts of the drive element, the electric motor, and driven by the fan coupling.

Figure 1 shows an industrial fan that has undergone diagnostics. 


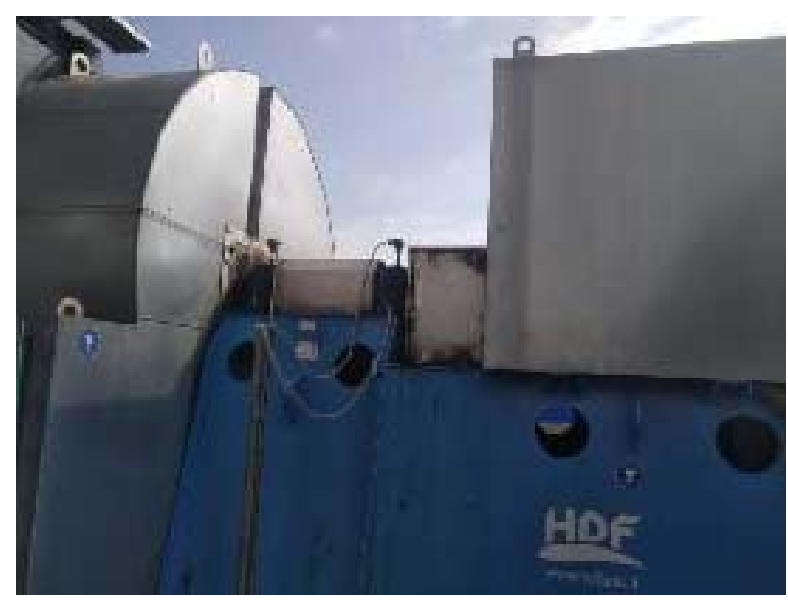

Fig. 1. Industrial fan $25 \mathrm{~Hz}$

The device for measuring and analyzing vibrations obtained data on the stage of the system and whether it is necessary to make corrections on it to bring the system to optimal operating condition.

Figure 2 shows the spectral analysis of the measured vibrations before any correction procedure.
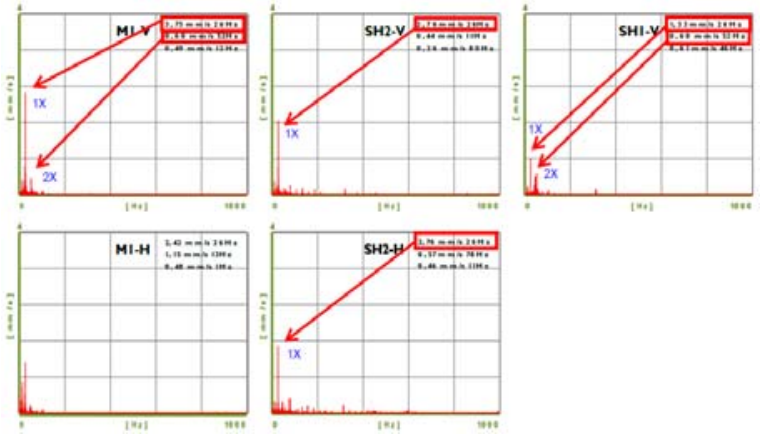

Fig. 2. FFT analysis of industrial fan condition $25 \mathrm{~Hz}$

From the Figure 2, it is possible to determine the pronounced $1 x$ and $2 x$, which are located next to it in radial directions, indicating an angular and parallel mismatch in the system. Critical peaks in the spectrum are indicated.

Table 1 shows the values of measured vibrations in three axes $(x, y, z)$.

Table 1. Vibrations values in three axes

\begin{tabular}{|c|c|c|c|c|c|c|c|}
\hline \multicolumn{7}{|c|}{ VIBRATION: } \\
\hline Veff.[mm/s] - BNL [dB] \\
\hline Moint & Vertical & \multicolumn{1}{c|}{ Horizontal } & \multicolumn{2}{c|}{ Axial } & rpm \\
\hline M2 & 3,18 & 22 & 3,44 & 23 & 2,48 & 14 & 1528 \\
\hline SH1 & 2,94 & 30 & 2,00 & 20 & 1,69 & 23 & 1529 \\
\hline SH2 & 2,78 & 23 & 1,37 & 26 & 1,88 & 23 & 1529 \\
\hline
\end{tabular}

\subsection{Fan shaft alignment procedure}

After the initial measurements of the condition of the technical system of the industrial fan, it was established according to the analysis of the FFT diagram that the fan's axis in relation to the electric motor is outside the tolerant axis. Based on the obtained diagnostic results, the axis correction is approached based on the measured values and the obtained real state of the axis deviation in relation to the other axis with the EasyLaser XT440 laser device.

Figure 3 shows the measured results before and after the alignment process along the horizontal and vertical axes.

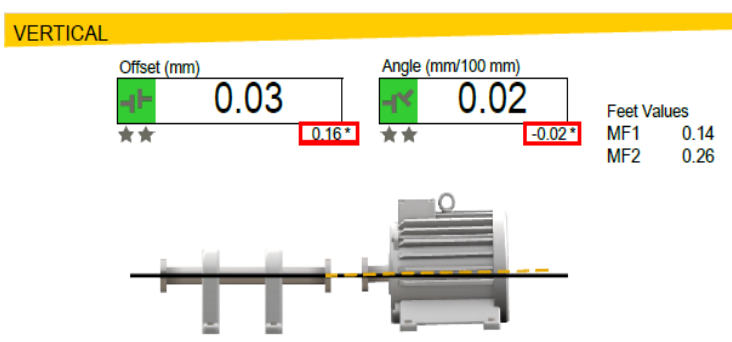

Fig. 3. Measured values of alignment in the vertical direction electric motor-fan

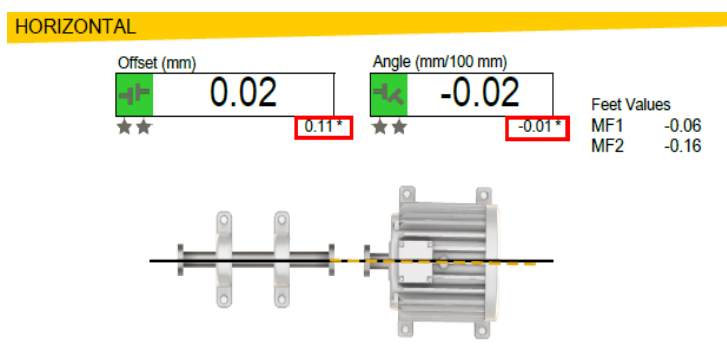

Fig. 4. Measured values of alignment in the horizontal direction electric motor-fan

From the Figures 4 it can be diagnosed that the axes diverged in both directions (horizontal and vertical). In the vertical direction, the current state was $0.11 \mathrm{~mm}$ in parallel and $-0.01 \mathrm{~mm}$ in the angle of misalignment. In the horizontal direction, 0.16 $\mathrm{mm}$ in parallel and $-0.02 \mathrm{~mm}$ in angle.

After corrections, the axes were brought to tolerance, so the values obtained are now along the horizontal axis $0.02 \mathrm{~mm}$ in parallel and -0.02 per angle, while in the vertical axis, along with the parallel $0.03 \mathrm{~mm}$, and at an angle 0, $02 \mathrm{~mm}$.

The results obtained from the software report are shown in Figure 5. 


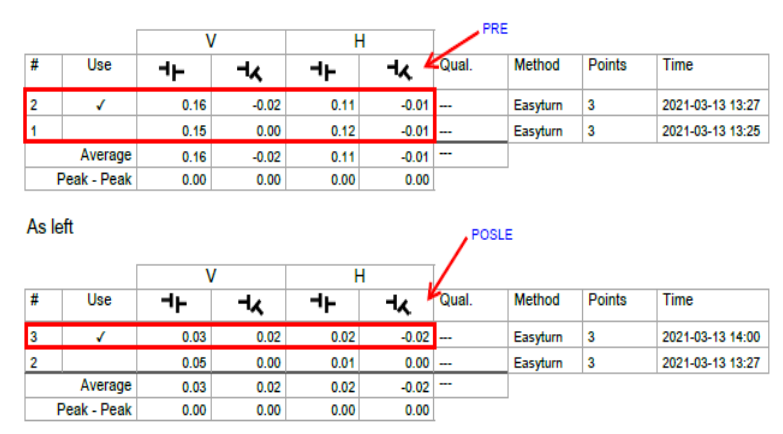

Fig. 5. Data on measured and corrective values of mismatch are presented

After the system's alignment, the remeasurement of vibrations is approached as a relevant indicator of whether the vibrations have decreased due to corrective measures on the said system. Figure 6 shows the spectral analysis of vibrations after the implementation of laser alignment of the shaft of an industrial fan and a drive electric motor via a coupling.
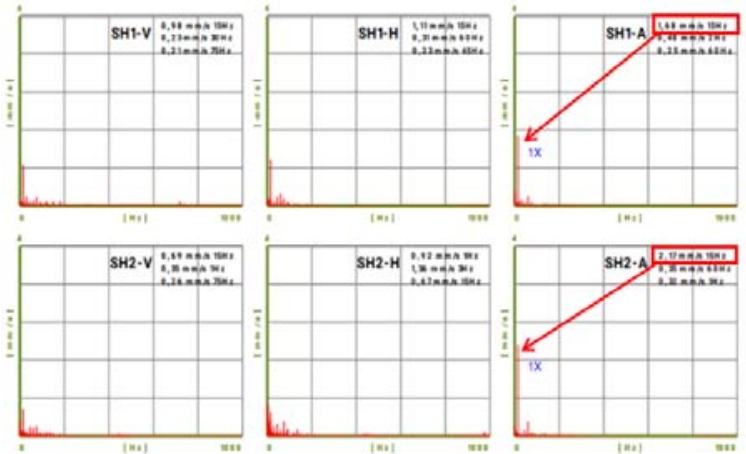

Fig. 6. FFT analysis after laser shaft alignment procedure

From Figure 6, according to the spectrum, vibrations can be determined to a lesser extent than the original state. Since the second peak on the diagram is lost after laser alignment, it is clear that it has been removed. For preventive measures, $1 \mathrm{x}$ on the diagram gives a signal that the impeller is slightly unbalanced and that the following corrective measure balances the impeller of the industrial fan. The measured vibrations were within the allowed limits and did not exceed $4.5 \mathrm{~mm} / \mathrm{s}$, which means that the system is in optimal operating condition.

Table 2 shows the measured values of vibrations in the $x, y$, and $z$ axes.
Table 2. Vibration after the process of coupling alignment

\begin{tabular}{|c|c|c|c|c|c|c|c|}
\hline \multicolumn{7}{|c|}{ VIBRATION: } \\
\hline Point & Vertical & \multicolumn{2}{|c|}{ Horizontal } & \multicolumn{2}{c|}{ Axial } & rpm \\
\hline M1 & 1,04 & 22 & 1,63 & 23 & 1,83 & 15 & 1,529 \\
\hline M2 & 1,59 & 29 & 1,78 & 20 & 1,99 & 21 & 1,529 \\
\hline SH1 & 0,98 & 24 & 1,12 & 26 & 1,68 & 23 & 1,529 \\
\hline SH2 & 0,89 & 23 & 0,92 & 25 & 2,17 & 21 & 1,529 \\
\hline
\end{tabular}

3.2 Results of research on the influence of shaft non-alignment on the service life of a ball bearing of an electric motor

As already mentioned in the introduction, when non-alignment occurs, the accompanying elements in the system are overloaded. A common case of this phenomenon is the incorrect fit of the shaft inside the bearing, which further causes increased vibrations, increased friction, and heating, which ultimately leads to a reduced service life of the bearing and its final failure before the scheduled time. The process of alignment is shown below in order to prevent bearing failure. On an identical system, a study of the durability of a cylindrical ball SKF bearing was performed. Basic data on the tested bearing are shown in Table 3 .

Table 3. Basic data on the tested bearing

\begin{tabular}{|l|c|}
\hline \multicolumn{1}{|c|}{ Technical data } & Dimensions \\
\hline Inner diameter & $90 \mathrm{~mm}$ \\
\hline Outer diameter & $160 \mathrm{~mm}$ \\
\hline Width & $30 \mathrm{~mm}$ \\
\hline Dynamic load & $208 \mathrm{kN}$ \\
\hline Limiting speed & $5,000 \mathrm{~min}^{-1}$ \\
\hline
\end{tabular}

The duration of the ball bearing was measured in relatively modest operating conditions since the industrial fan system is located outside the closed space, i.e., it is exposed to external influences.

Both fan systems have a slight observed misalignment, with the process of alignment being started on one fan, and on the other, the system was left to function under some partially satisfactory circumstances within the system itself. This experimental research aims to observe in the time difference the optimal operation of the system, i.e., that the vibrations in the systems at the measuring points of the bearings do not increase above $4.5 \mathrm{~mm} / \mathrm{s}$, which is allowed for this operating class of machines according to ISO standard. 
Based on previous research on bearing life [20] and calculations, the measured values of actual service life under both conditions and theoretical service life were compared.

Bearing life in duty cycles can be expressed in:

$$
L_{10}=\left(\frac{C}{p}\right)^{n}
$$

The service life of the bearing in working hours is calculated using the form:

$$
L_{10}=\frac{\left(\frac{C}{P}\right)^{n} * 1000000}{N(60)}
$$

By implementing equations, 2 and 3, data on the service life of the ball bearing under ideal conditions were obtained, which in practice often turns out to be incorrect or partially true, so appropriate tolerable time deviations from the calculation must be given.

According to equation 2 , the service life of bearings in operating cycles is 54,093 cycles, i.e., the service life of the bearing in working hours according to equation 3 is $58,964 \mathrm{~h}$.

After calculating the theoretical service life (TLB), the measurement and analysis of vibrations at the measuring points of the front and rear bearings of the electric motor were started. Table 4 shows the vibration values after the potential bearing failure at the rear of the electric motor.

Table 4. Vibrations due to non-implementation of the alignment process

\begin{tabular}{|c|c|c|c|c|c|c|c|}
\hline \multicolumn{7}{|c|}{ VIBRATION: } \\
\hline Point & Vertical & \multicolumn{2}{|c|}{ Horizontal } & \multicolumn{2}{c|}{ Axial } & rpm \\
\hline M1 & 2,47 & 22 & 2,14 & 23 & 2,76 & 32 & 1529 \\
\hline M2 & 2,01 & 29 & 1,99 & 20 & 5,11 & 24 & 1529 \\
\hline SH1 & 1,01 & 24 & 1,15 & 26 & 1,89 & 23 & 1529 \\
\hline SH2 & 0,97 & 23 & 0,94 & 25 & 2,26 & 21 & 1529 \\
\hline
\end{tabular}

By analyzing the obtained values from Table 4, on the observed system on which no alignment was done, it can be concluded that after the appropriate time, there was an increase in vibration, especially in the position of the rear bearing of the electric motor in the axial axis, which indicates that the bearing has potential damage.
Figure 7 shows a detailed analysis of bearing failure via spectral analysis.

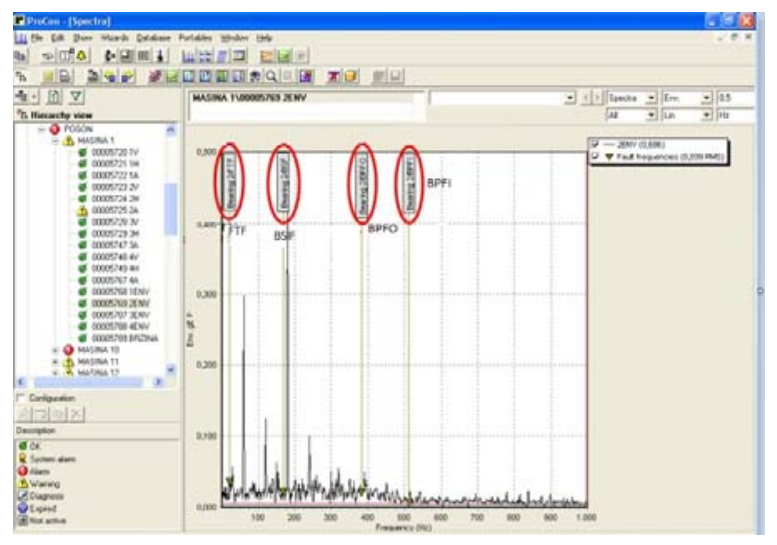

Fig. 7. Bearing failure spectral analysis

Figure 7 clearly shows the pronounced peaks in the frequency spectrum indicating the failure of the bearing cage itself and the partial potential failure of the balls at an early stage.

\subsection{Comparative analysis of two systems - on which alignment was done and on which alignment was not done}

Since the failure of the bearings on the fan system on which the alignment process was not performed was established, a comparative analysis of the longevity of the bearings on two identical systems, on the system on which the laser alignment process was accessed, and on the system where it was not performed. This comparative analysis should indicate the importance of applying the axis alignment technique to the reliability of technical systems.

Figure 8 shows a diagram of a comparative analysis of the bearing life under optimal operating conditions of the system on the system on which the alignment process was performed. The observed bearing functioned completely correctly for a full period of two and a half years, i.e., a period of about 23,650 hours of work (RBL). According to the tolerance limit (TLL) set by the employers, the bearing met the technical expectations.

Figure 9 shows the service life of a roller bearing in the case when the alignment process is not performed on an identical technical system of an industrial fan. 


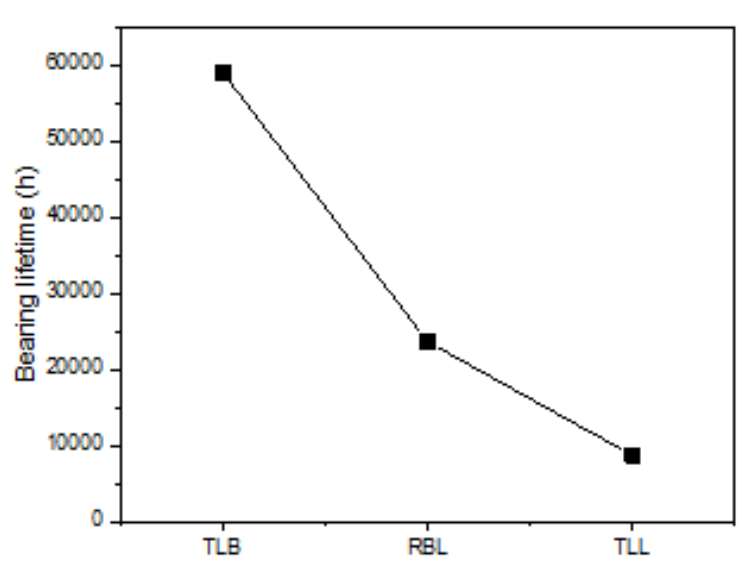

Fig. 8. Comparative analysis of bearing life during the alignment process

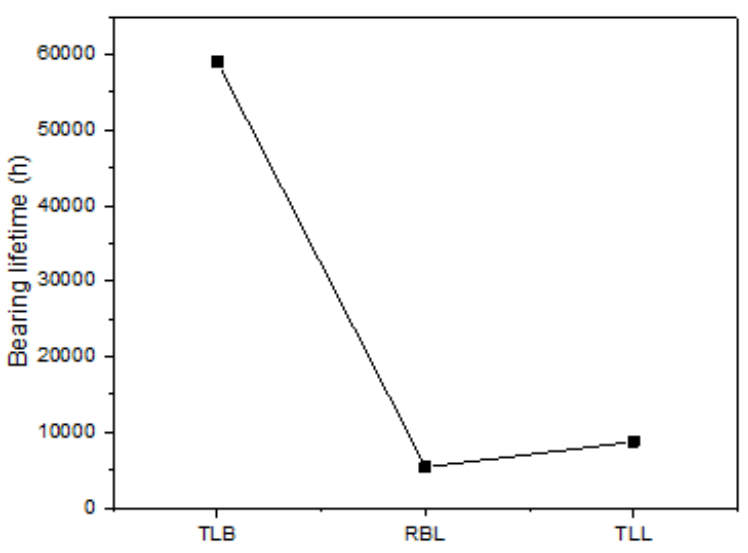

Fig. 9. Comparative analysis of bearing life in case of shaft misalignment

From Figure 9, it can be seen that the bearing failed before the tolerance limit of the service life was set, more precisely, it failed after 5400 operating hours. These data indicate that the bearing exposed to excessive load by a nonalignment shaft did not meet the expected technical expectations.

\section{CONCLUSION}

Predictive maintenance is one of the main features of modern ways of maintaining technical systems. In order to implement and carry out predictive maintenance in a quality manner, it is first of all necessary to analyze in detail the System that maintenance deals with. After knowing all the advantages and disadvantages of the technical System that should be subjected to the predictive type of maintenance, a detailed analysis is approached, i.e., technical diagnostics.

Misalignment and increased vibrations due to this phenomenon are among the most common cases in industrial systems. This problem further develops more serious problems within the system, curved shaft, bearing failure, coupling defect, and the like. The application of predictive maintenance ultimately reduces costs, especially when the costs are related to unplanned shutdowns of machines and production, which leads to the highest percentage of costs.

The conducted research has shown that the precise laser alignment technique leads to achieving the projected bearing life. The technical system on which the work was done fulfilled the technical expectations of the bearing life prescribed by the manufacturer, reaching a working life of 23,650 working hours. The technical system on which no alignment was performed was exposed to excessive load by the non-alignment shaft, and it did not meet the anticipated technical expectations, and it failed at 5,400 hours of work. Research has shown that the application of alignment can increase the service life of bearings by 4.38 times on a shaft on which no alignment has been performed.

\section{REFERENCES}

[1] D.L. Rivera, M.R. Scholz, M. Krauss, K. Schilling, Towards a Predictive Maintenance System of a Hydraulic Pump: IFAC 51(11), 2018: 447-452.

https://doi.org/10.1016/j.ifacol.2018.08.346

[2] C.S. Byington, M.J. Roemer, T. Galie, Prognostic enhancements to diagnostic systems for improved condition-based maintenance [military aircraft], IEEE Aerospace Conference 2002, Montana, USA, pp.2815-2824.

https://doi.org/10.1109/AERO.2002.1036120

[3] A. Voisin, E. Levrat, P. Cocheteux, B. lung, Generic prognosis model for Proactive Maintenance Decision Support: Application to Pre-Industrial E-maintenance Test Bed. Journal of Intelligent Manufacturing. 21, 2010: 177-193 https://doi.org/10.1007/s10845-008-0196-z

[4] A.K. Jardine, Optimizing condition based maintenance decisions, Annual Reliability and Maintainability Symposium 2002, LA: IEEE, pp.90-97.

https://doi.org/10.1109/RAMS.2002.981625

[5] B. Novaković, Lj. Radovanović, R. Ivetić, V. Šinik, M. Đurđev, L. Đorđević, CBM ConceptPredicitive Maintenance - Vibration Analysis and Balancing Process of Industrial Fans, $X$ International Conference Industrial Engineering and Environmental Protection 2020 (IIZS 2020), $9^{\text {th }}$ October, 2020, Zrenjanin, Serbia, pp.208-213. 
[6] D. Mikić, E. Desnica, A. Ašonja, Ž. Adamović, Monitoring the State of the Technical o System in the Exploitation, IV International Conference Industrial Engineering And Environmental Protection 2014 (IIZS 2014), 15 ${ }^{\text {th }}$ October, 2014, Zrenjanin, Serbia, pp.179-188.

[7] S. Amari, L. McLaughlin, H. Pham, Cost-effective Condition-Based Maintenance Using Markov Decision Processes, Reliability and Maintainability Symposium 2006, Newport Beach, California, pp.464-469.

https://doi.org/10.1109/RAMS.2006.1677417

[8] B. Li, M-Y. Chow, Y. Tipsuwan, J.C. Hung, Neural-network-based Motor Rolling Bearing Fault Diagnosis. IEEE Transactions on Industrial Electronics, 47 (5), 2000: 1060-1069.

https://doi.org/10.1109/41.873214

[9] A.K. Jalan, A.R. Mohanty, Model Based Fault Diagnosis of a Rotor-bearing System for Misalignment and Unbalance Under Steadystate Condition. Journal of Sound and Vibration 327 (3), 2009: 604-622.

https://doi.org/10.1016/j.jsv.2009.07.014

[10] T.H. Patel, K.D. Ashish, Experimental Investigations on Vibration Response of Misaligned Rotors. Mechanical Systems and Signal Processing, 23 (7), 2009: 2236-2252.

https://doi.org/10.1016/j.ymssp.2009.04.004

[11] K. Wu, Z. Liu, Q. Ding, Vibration responses of rotating elastic coupling with dynamic spatial misalignment. Mechanism and Machine Theory, 151, 2020: 103916.

https://doi.org/10.1016/j.mechmachtheory.2020.1 $\underline{03916}$

[12] W. Zhao, C. Hua C., D. Wang D., D. Dong, Fault Diagnosis of Shaft Misalignment and Crack in Rotor System Based on MI-CNN, In: Wahab M. (eds) Proceedings of the 13th International Conference on Damage Assessment of Structures, Springer, Singapore, 2020.

https://doi.org/10.1007/978-981-13-8331-1 39
[13] D. Mikić, E. Desnica A. Ašonja, B. Stojanović, Reliability Analysis of Ball Bearing on the Crankshaft of Piston Compressors. Journal of the Balkan Tribological Association, 22 (4-IV), 2016: 5060-5070.

[14] E. Desnica, A. Ašonja, D. Mikić, B. Stojanović, Reliability of Model of Bearing Assembly on an Agricultural of Cardan Shaft. Journal of the Balkan Tribological Association, 21 (1), 2015: 38-48.

[15] A. Ašonja, E. Desnica, Reliability of Agriculture Universal Joint Shafts Based on Temperature Measuring in Universal Joint Bearing Assemblies. Spanish Journal of Agricultural Research, 13 (1), 2015: 1-8.

[16] A. Ašonja, Ž. Adamović, N. Jevtić, Analysis of Relyability of Cardan Shafts Based on Condition Diagnostics of Bearing Assembly in Cardan Joints. Journal Metalurgia International, 18 (4), 2013: 216-221.

[17] S. Tenev. Alignment Optimization of 3D Model of Propulsion Shaft System, IOP Conf. Series: Materials Science and Engineering, 977 (2020), 012008, IOP Publishing.

http://doi.org/10.1088/1757-899X/977/1/012008

[18] X. Xu, Y. Kang, Z. Qiu, B. Wang, Calibration Method for a Laser-based Alignment System, Proceedings - Eleventh International Conference on Information Optics and Photonics (CIOP 2019), 11209, Xi'an, China.

https://doi.org/10.1117/12.2543016

[19] D. Luo, C. Kuang, X. Hao, X. Liu, High-precision Laser Alignment Technique Based on Spiral Phase Plate. Optics and Lasers in Engineering, 50 (7), 2012: 944-949.

https://doi.org/10.1016/j.optlaseng.2012.02.010

[20] A. Ašonja, A. Pastuhov, The Influence of Diagnostic State of Reliability of Agriculture Double Cardan Shaft. Agricultural Engineering, 39 (1), 2014: 21-30. 